\title{
Water motion on coral reefs: evaluation of the 'clod card' technique
}

\author{
Paul L. Jokiel ${ }^{1}$, Janice I. Morrissey ${ }^{2}$ \\ ${ }^{1}$ Hawaii Institute of Marine Biology, PO Box 1346, Kaneohe, Hawaii 96744, USA \\ ${ }^{2}$ Great Barrier Reef Marine Park Authority, PO Box 1379, Townsville, Queensland 4810, Australia
}

\begin{abstract}
Assumptions underlying the technique of using dissolution rates of plaster blocks as a dimensionless index of water motion were tested. 'Diffusion factor' (DF) was originally defined by Doty (1971) as the ratio of weight of material dissolved from an experimental block to that of a control block maintained simultaneously in calm water. The DF concept must be interpreted with caution because measurement of the rate of loss in the control block is influenced by many factors. The volume of standing water containing the control block must be relatively large in order to avoid saturation of the water with solute from the card. Temperature and salinity also influence rate of weight loss. Relationship between current velocity and weight loss was linear over the range of current velocities tested 0 to $47 \mathrm{~cm} \mathrm{~s}^{-1}$ ). Weight loss remained relatively constant until the block dissolved to less than $30 \%$ of its original weight. The DF measurement is analogous to various dimensionless indices of mass transfer currently being applied in coral reef hydrodynamics. Weight loss due to turbulence (i.e. wave-induced orbital motion) and weight loss due to unidirectional flow (i.e. current) apparently are additive, but in a complex fashion. Exemplary data are presented to illustrate the utility as well as the limitations of this method on coral reefs.
\end{abstract}

\section{INTRODUCTION}

The concept of using the dissolution rate of a solid as an index of 'water motion' was introduced by McConnel \& Siegler (1959), who showed that weight loss in tablets of sodium chloride during 1 min immersion periods was a useful index of current speed in streams. Muus (1968) developed a method using $6 \mathrm{~g}$ plaster spheres mounted on steel rods that allowed longer exposure time ( $2 \mathrm{~h}$ ). Doty (1971) further modified this technique. Use of much larger $(30 \mathrm{~g})$ plaster blocks or 'clods' glued to plastic cards facilitates attachment to the bottom and allows long-term (generally $24 \mathrm{~h}$ ) integrated measurements of water motion regimes encountered by benthic organisms. The clods can be tied directly to hard substrata or corals. For measurements on sand or mud substrata, the cards can be attached to stakes or tied to bricks or dive weights and placed directly on the bottom.

Doty suggested that the weight loss of experimental clod cards (termed card value or $C V$ ) held in moving water can be divided by the weight loss of identical cards held in calm water. He reasoned that weight loss in the control card was limited only by diffusion, hence the ratio of weight loss in the experimental blocks to weight loss in the calm water 'control' is a dimensionless index that should describe the magnitude of diffusion enhancement due to water motion. This ratio was termed 'diffusion factor' $(D F)$ and was regarded as a basic physical parameter that is independent of the materials and methods used by different investigators.

Other workers subsequently developed clods that can be used in situations requiring longer field exposures. Grovhoug (1978) devised a slow-dissolving solid consisting of a mixture of plastic resin glue and commercial wall-patching compound. Gerard \& Mann (1979) added latex paint to the plaster of Paris mixture in a $1: 4$ ratio in order to produce a solid that dissolved at a slow rate. Kawai et al. (1982) utilized large (500 g) hemispherical plaster blocks to allow measurements in extremely turbulent environments. 
These basic techniques and concepts have provided biologists with an inexpensive, flexible and highly practical method for measurement of water motion on reefs (e.g. Russo 1977, Santelices 1977, Jokiel 1978, Gerard \& Mann 1979, Agegian 1985, Morrissey 1985). The assumptions and concepts that underlie use of the clod card method and interpretation of the results have gone untested. Questions arise as to what is being measured and how the results are to be interpreted. In this investigation we undertook a series of experiments to describe the following:

(1) rate of weight loss through time with decreasing mass of clod;

(2) relationship between weight loss in the calm water 'control' cards and volume of water in the calibration chamber;

(3) effect of temperature on weight loss;

(4) effect of salinity on weight loss;

(5) effect of current velocity on weight loss and evaluation of $D F$ as measured with 2 different clod card formulations; and

(6) effect of different flow regimes on weight loss and $D F$, with emphasis on effect of current versus the effect of waves.

\section{MATERIALS AND METHODS}

Clod card formulation and manufacture. Clod cards were prepared according to the general instructions of Doty (1971). The clods were molded in $50 \mathrm{ml}$ tapered plastic beakers to produce a symmetrical shape. The first type of clod (fast-dissolving or F-type) was formed from commercial plaster of Paris prepared according to Doty's (1971) instructions. The second type (slow-dissolving or S-type) was formed from a mixture of powdered plastic resin glue (Weldwood Brand, Weldwood Packaged Products, Champion International Corporation, Kalamazoo, MI 49003, USA) and commercial wall patching compound (Fixall Brand, Dowman Products Inc., Long Beach, CA 90813, USA) according to the instructions of Grovhoug (1978). The components were mixed in the ratio (by volume) of 1 part powdered glue to 10.5 parts wall patching compound to 5.1 parts water. The powdered components were thoroughly mixed before water was added. Extreme care was taken to remove all bubbles. The molds were filled and held on a vibrating laboratory vortex mixer and then tapped vigorously against the table top until bubbles stopped rising to the surface (about $1 \mathrm{~min}$ of tapping). The mix was allowed to harden for $48 \mathrm{~h}$ at room temperature ( 23 to $25^{\circ} \mathrm{C}$ ). The clods were removed from the molds and the flat bases were filed and sanded to bring all clods to a weight of $50 \pm 0.5 \mathrm{~g}$. Next, the clods were glued to water-resistent plastic cards with water-proof contact cement (Fastbond 10 Brand Contact Cement, 3M Company, St Paul, MN 55101, USA). Holes were punched in both ends of the plastic card to allow fastening of the cards to substrata in the field.

Before using, the S-type clod cards were soaked in seawater for $24 \mathrm{~h}$, rinsed with fresh water, blotted and then weighed to the nearest $0.1 \mathrm{~g}$. The initial weight was recorded on the card along with an identification number. After use, the excess water was blotted off the cards and they were again weighed. In contrast, the plaster of Paris cards (F-type) were allowed to dry before initial weighing. The weight of the plaster cards is influenced by extreme changes in humidity, but this problem can be avoided by drying the clods to constant weight in an air-conditioned (low humidity) environment. The dry cards were weighed and identified by a number written on the plastic base. These cards were not pre-soaked prior to use. At the end of the measurement period the cards were removed from the water and again allowed to air-dry to a constant weight.

The 2 methods of wet weighing and dry weighing have different advantages. Wet weighing gives an immediate result, but an accurate weighing balance must always be available. The dry method is useful at remote field sites that lack such instrumentation. Field studies of water motion conducted at Johnston Atoll $\left(16^{\circ} 44^{\prime} \mathrm{N}, 169^{\circ} 32^{\prime} \mathrm{W}\right)$ are presented in this paper as examples of this application. The pre-weighed dry cards can be used directly in the field. After exposure, they can be partially air-dried at the field location and subsequently returned to the laboratory for final drying and weighing.

\section{EXPERIMENTS}

Expt 1. Linearity of weight loss over time. A clod card becomes smaller as it dissolves. The total surface area decreases, but the surface to volume ratio increases. Obviously, rate of dissolution over time could be non-linear. Rate of weight loss was measured by placing S-type clods in $20 \mathrm{l}$ of calm sea water and reweighing them at regular time intervals as they dissolved. The water was replaced daily to avoid saturation effects of solute. Water temperature during the test was $25^{\circ} \mathrm{C}$ and salinity $34 \%$.

Expt 2. Effect of calibration container volume. Water in the calibration chamber could eventually become saturated with solute, preventing further dissolution. Saturation of the water in the calibration chamber would result in an artificially low control value. The weight loss of blocks held in a chamber is considered to represent calm-water diffusion and is used as the denominator in the DF calculation. Possible error was 
evaluated by measuring $24 \mathrm{~h}$ weight loss of S-type clods in a series of 20 containers containing seawater volumes ranging from 0.5 to $35 \mathrm{l}$. All were run simultaneously at a temperature of $25^{\circ} \mathrm{C}$ and a salinity of $34 \%$. Weight loss of cards versus water volume was analyzed.

Expt 3. Effect of temperature. Fast-dissolving clods were held in containers holding $20 \mathrm{l}$ of calm seawater at $34 \%$ for $24 \mathrm{~h}$ at a series of temperatures ranging from 18 to $32^{\circ} \mathrm{C}$. The relationship between weight loss and temperature was analyzed.

Expt 4. Effect of salinity. Fast-dissolving clods were held in calm water volumes of $20 \mathrm{l}$ for $24 \mathrm{~h}$ in series of salinities ranging from 0 to $34 \%$ at a temperature of $25^{\circ} \mathrm{C}$. The relationship between weight loss and salinity was analyzed.

Expt 5. Effect of current velocity and clod card formulation. Unidirectional current relative to the clods was produced by moving the cards through calm water at a constant speed. The test was conducted in a salt water pool ( $6 \mathrm{~m}$ wide $\times 20 \mathrm{~m}$ long $\times 1.5 \mathrm{~m}$ deep) that was subjected to steady trade winds of 20 to $30 \mathrm{~km} \mathrm{~h}^{-1}$. Temperature was $25^{\circ} \mathrm{C}$ and salinity $34 \%$. A horizontal beam $5 \mathrm{~m}$ in length was suspended from a hub and axle which was rotated by a electric motor. Clod cards (both F- and S-types) were attached to thin flat vanes that projected downward from the rotating beam into the water. These knifed through the water and did not appear to create any turbulence. The beam was rotated at constant speed. Velocity of the water $(V)$ relative to a clod attached at a given radius on the beam was calculated from the formula $V=2(3.14) r t^{-1}$, where $t=$ elapsed time for 1 rotation of the beam; and $r=$ distance of the card from the axle.

Velocity increased with increasing radius and ranged from 2 to $47 \mathrm{~cm} \mathrm{~s}^{-1}$. Cards were attached at various distances along the beam to allow simultaneous measurements over a wide range of velocities. Observation of dye spots and neutrally buoyant particles in the water showed that movement of the clod array did not induce a current in the deep pool. Apparently the motion of the cards through the water was insufficient to overcome the inertia of the large water mass. Control cards were held in a covered submerged $20 \mathrm{l}$ bucket at the same temperature and salinity as the experimental cards.

Expt 6. Field studies. Pre-weighed dry plaster of Paris cards (F-type) were prepared in Hawaii and later taken to Johnston Atoll for use in a field study (Jokiel \& Tyler in press). Large ocean swell breaking along the outer peripheral margin of this atoll washed over the ocean reef crest and into the lagoon, creating an extremely strong unidirectional current across the ocean reef flat and back reef. Clod cards were attached to corals and coral rocks at various points along a transect running from the ocean reef crest 'downstream' into deeper lagoon water. An isolated 'patch reef' located in the lagoon at a point $2 \mathrm{~km}$ downstream from the ocean reef study site was also investigated. Clods were attached at various depths from the reef flat to the lagoon floor. After $24 \mathrm{~h}$ of simultaneous exposure at both sites, the clods were removed, air-dried for several days and shipped to Hawail for final drying and weighing. Control cards were held in a covered submerged 201 bucket at the same temperature and salinity as the experimental cards. Data on coral coverage were also taken (Jokiel \& Tyler in press).

\section{RESULTS}

\section{Linearity of weight loss over time}

Results of the weight loss over time experiment are shown in Fig. 1. Weight loss was essentially linear until the clod dissolved to approximately $30 \%$ of its original weight. These results are consistent with those of Grovhoug (1978). Error caused by clod cards dissolving to less than $30 \%$ of their initial weight can be eliminated by shortening exposure time and/or substituting a material that dissolves at a slower rate.

\section{Effect of calibration container volume}

Results of the water volume versus 24 h weight loss are shown in Fig. 2. Weight loss increased rapidly with increasing calibration volume up to a volume of $20 \mathrm{l}$ after which there was little change in weight loss with increasing water volume. The most likely explanation is that a dissolving solid can saturate the calibration water and prevent further dissolution. The calm water measurement used in the calculation of $D F$ with a $50 \mathrm{~g}$

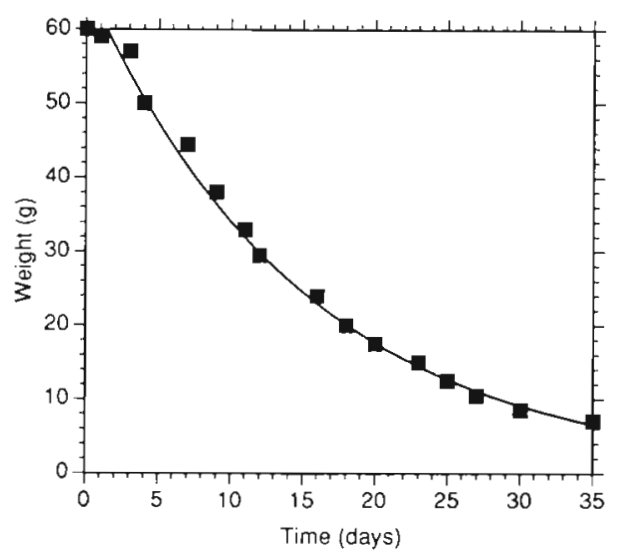

Fig. 1. Weight of clods (slow-dissolving wet type) through time at $S=34 \%$ and $\mathrm{T}=25^{\circ} \mathrm{C}$. Each point represents the mean of 3 observations 


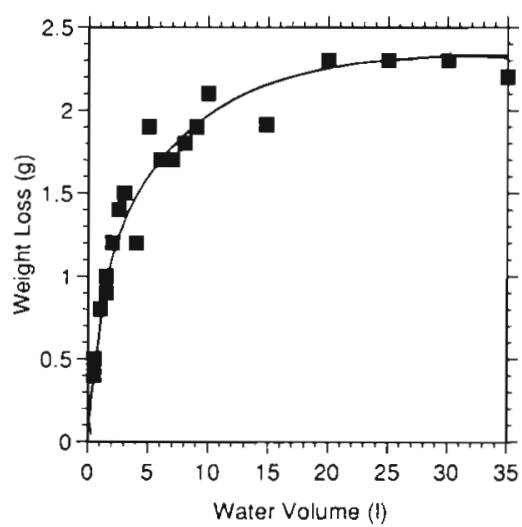

Fig. 2. Calibration water volume (at $\mathrm{S}=34 \%, \mathrm{~T}=25^{\circ} \mathrm{C}$ ) versus weight loss in $\mathrm{S}$-type clod cards

clod must be measured in a container with a minimum volume of $20 \mathrm{l}$ if it is to truly represent weight loss due to diffusion in totally calm water.

\section{Effect of temperature}

Results of weight loss versus temperature are shown in Fig. 3. Dissolution increases linearly over this range. Weight loss doubles between 18 and $32^{\circ} \mathrm{C}$.

\section{Effect of salinity}

The relationship between salinity and weight loss in the clod cards is shown in Fig. 4. The clod cards dissolved at a slower rate in fresh water. Dissolution rate appeared to increase with increasing salinity from 0 to $15 \%$. Above a salinity of $15 \%$, the dissolution rate decreased with increasing salinity. The resulting curvilinear relationship probably is related to solubility, buffering capacity and $\mathrm{pH}$ change in the different salinity treatments. Plaster of Paris is composed of calcium sulfate. Calcium ion and sulfate ion are major constituents

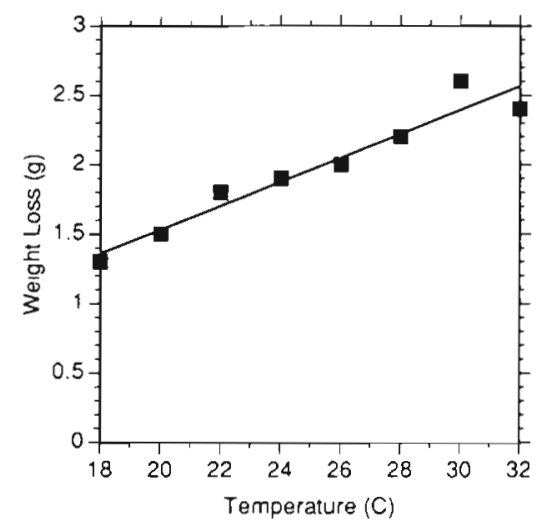

Fig. 3. Effects of temperature (at $34 \%$ ) on weight loss in F-type clod cards

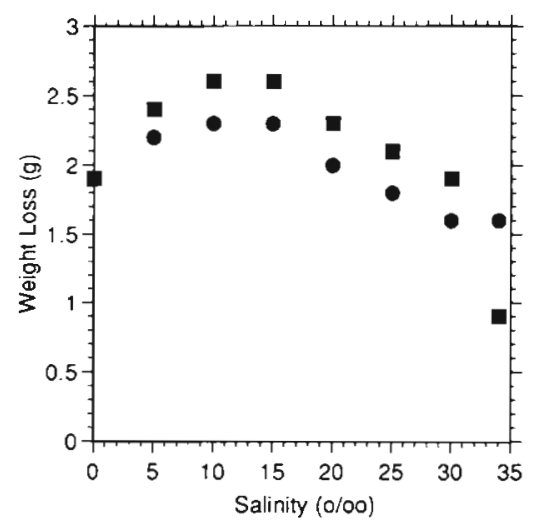

Fig. 4. Effect of salinity (at $25^{\circ} \mathrm{C}$ ) on weight loss of F-type clod cards. ( $)$ and $(-$ represent replicate experiments

of seawater. The relationship between clod weight loss and salinity is essentially linear, however, over the range of salinity from 20 to $34 \%$. The point to be made, however, is that calibration of the control must be carried out at the same salinity as the experimental clod card

\section{Effect of current velocity and clod card formulation}

The relationships between flow velocity $(V)$, clod weight loss in $\mathrm{g}$ (card value or $C V$ ) and diffusion factor $(D F)$ measured with $20 \mathrm{l}$ calibration chambers are shown in Table 1 for F-and S-type clods. The linear correlation between velocity and weight loss in the cards ( $C V$ ) is very high ( $r=0.97$ to 0.99 ). Weight loss in the F-type formulation is about twice that of the S-type formulation as shown by the slope and $y$-intercept. Normalization of the $C V$ values to the calm-water control produces similar $D F$ results for both formulations. Regression lines of $D F$ versus current for both card formulation have the same slope. The $y$-intercept for the F-type card is as predicted, but is slightly higher for the S-type card. The offset of 0.3 will produce little comparison error in the normal field measurements. $D F$ values encountered on reefs generally range between 5 and 25 (Figs. $5 \& 6$ ). Obviously, comparisons between

Table 1. Relationship between flow velocity $(V)$ in $\mathrm{cm} \mathrm{s}^{-1}$, weight loss $(C V)$ in $g$ and diffusion factor $(D F)$ for the fastdissolving ( $F$ ) and slow-dissolving (S) clod formulations

\begin{tabular}{|lccc|}
\hline Clod type & Relationship & r & $n$ \\
\hline F & $C V=0.6 V+9.0$ & 0.99 & 20 \\
F & $D F=0.06 V+1.0$ & 0.99 & 20 \\
S & $C V=0.3 V+5.8$ & 0.97 & 22 \\
S & $D F=0.06 V+1.3$ & 0.97 & 22 \\
\hline
\end{tabular}



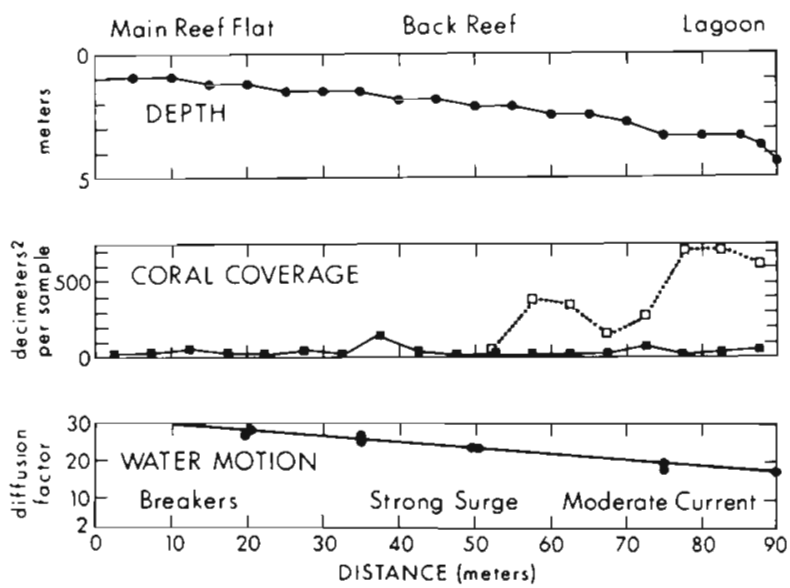

Fig. 5. Depth, coral coverage and water motion (DF) measured along a transect from the breaker zone on the ocean reef towards the Johnston Atoll lagoon (Jokiel \& Tyler in press). () Coverage by the dominant table coral Acropora cytherea (Dana, 1846); ( 1 ) coverage by all other species

results of various studies using different clod card formulations would be facilitated if the results were expressed as $D F$ rather than weight loss in $g$.

\section{Field studies}

Measurements made on the ocean reef at Johnston Atoll are presented in Fig. 5. The regression equation of water motion (DF) on depth $(Z)$ for the clod card data obtained in this area is:

$$
D F=-4.5 Z+33.4(\mathrm{r}=0.86)
$$

Current speed must diminish in direct proportion to the increase in depth as the water moved downstream.
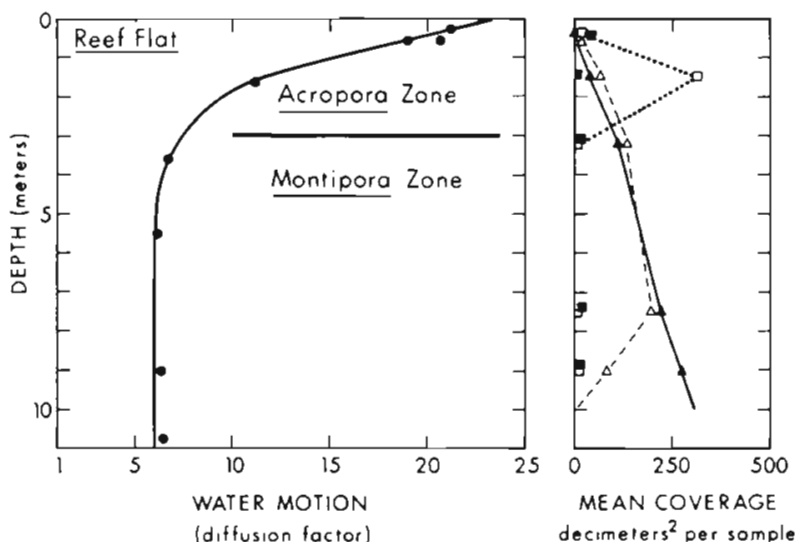

Fig. 6. Water motion (DF) versus depth on a patch reef in the Johnston Atoll lagoon (left) compared to coral coverage of dominant species (right). (a) Acropora cytherea (Dana 1846); (4) Montipora verrilli Vaughan, 1907; (4) Montipora verrucosa Vaughan, 1907; (-) all other species combined
Therefore, we observe a linear relationship between $D F$ and water depth on the back reef.

Water motion for the lagoon patch reef that was located $2 \mathrm{~km}$ down-current of the main ocean reef is shown in Fig. 6. High water motion occurs at the surface, diminishing exponentially with depth to a constant $D F$ of 6.5 below a depth of $3 \mathrm{~m}$. These data illustrate 2 important points. First, high water motion values (DF exceeding 20) in the shallow water lagoon situations is caused mainly by the orbital motion of small wind-driven waves. The lagoon is protected from large ocean swell. Strong unidirectional surface currents do not occur here. Turbulence induced by winddriven waves was evident near the surface, and apparently can be extremely effective at increasing $D F$. The second point is that a $D F$ of 6.5 was measured below the layer influenced by small wind-driven surface waves. This 'background' value appears to be the same unidirectional current measured at a distance of $2 \mathrm{~km}$ upstream on the back reef. This unidirectional current was strong enough to be felt on the bottom while diving. Sediments stirred from the bottom were observed to move downstream. The mean cross-sectional water depth at the patch reef (calculated from soundings, charts and aerial photographs) was $5.8 \mathrm{~m}$. The measured $D F$ value of 6.5 is close to the calculated DF of 7.0 obtained by solving the back-reef regression equation and a depth value of $5.8 \mathrm{~m}$.

The exemplary data in Figs. $5 \& 6$ illustrate trends that are more fully described by Jokiel \& Tyler (in press). The table coral Acropora cytherea requires moderate water motion. It is excluded from the breaker zone by wave damage (Fig. 5) but flourishes in shallow-water lagoon environments where water motion is high due to passage of shallow wind-driven waves (Fig. 6). In calm water, 2 species of the foliaceous coral Montipora outcompete all other species at Johnston Atoll.

\section{DISCUSSION}

Many of the previously untested assumptions underlying the use and interpretation of the clod card method appear to be valid. Weight loss was linear over time until the clod decreased to $30 \%$ of its original weight. Weight loss was directly proportional to current speed over a wide range of measurements. The measurement is, however, sensitive to temperature and salinity of the water. These will not add an error where all the measurements are being taken simultaneously in the same water mass, as in the examples shown from Johnston Atoll.

The DF concept is potentially valuable as a dimensionless index of water motion. Accurate reporting of $D F$ in water-motion studies would facilitate compari- 
sons between various studies. The DF concept must be used with caution. Weight loss in the 'calm water control' is sensitive to volume of the calibration container as well as temperature and salinity of the water in the container. Use of $D F$ as an absolute measure of diffusion enhancement has potential value only if the calm-water control cards are held in a large container of water at the same temperature and salinity as the experimental card. The concept of $D F$ is very intriguing, and further work on the hydrodynamic and biological meaning of this parameter is being conducted.

$D F$ is a dimensionless index of water motion that is analagous to the Sherwood number $(S h)$, which assesses the relative importance of forced convection versus molecular diffusion in a mass transfer process. The Sherwood number is the ratio of measured mass flux assised by advection to the flux that would occur if molecular diffusion was the sole mechanism for mass transport (White 1988). The Sherwood number is extensively used in chemical engineering, and has recently been applied to studies of reef corals (Patterson et al. 1991). A detailed discussion of Sherwood number is beyond the scope of this paper, but in practice it is calculated as:

$$
S h=h_{\mathrm{m}} W / D
$$

where $h_{\mathrm{m}}=$ the mass transfer coefficient; $W=$ colony width or polyp width; and $D=$ the diffusion coefficient. The clods are all of the same size $W$, so $S h$ and $D F$ are both expressed as the ratio of enhanced flux in moving water divided by flux due to diffusion.

Another dimensionsless mass transfer number called the Stanton Number $\left(S t_{\mathrm{m}}\right)$ has been definded as the ratio of uptake rate to the rate of advection of the substance past the uptake surface. This parameter is also analagous to $D F$, and has been used on coral reefs to describe effect of current on phosphorus uptake (Atkinson \& Bilger 1992). The recent movement towards studies of mass transfer in coral reef systems using dimensionless indices has created a growing interest in the clod card method and use of $D F$ in hydrodynamic studies on coral reefs.

The clod card method appears to be an excellent means for determining an integrated relative water motion index in cases where all measurements are conducted simultaneously at the same temperature and salinity. Salinity and temperature in the control water must be the same as that of the water in the hydrodynamic field being measured. The calm-water control cards can be held in heavily weighted containers. Water in such properly held containers is essentially motionless, but the temperature and salinity are the same as for the experimental cards. A few small perforations in the container will allow restricted water exchange and will prevent saturation of the calibration chamber with solute. We must emphasize that the pails must be absolutely stationary. Such calibration containers can be held in large aquaria or in an extremely calm area of the reef. The validity of $D F$ depends on accurate calibration.

Problems of quality control can arise in the manufacture of the clods. Improper formulation and manufacture will produce a friable clod that will crumble during measurement. Air bubbles and other nonhomogeneities in the mixture can cause measurement errors. In field environments, mechanical damage, abrasion or disturbance by fish and other marine organisms can cause errors. An extreme example of this has been reported by K. Agegian (pers. comm.) in the Leeward Hawaiian Islands. At this location, curious Hawaiian monk seals removed plaster clods as soon as they were deployed unless the cards were covered with protective cages. Perhaps animals would not be attracted to the blocks if the glaring white color was masked by adding dye to the formulation to reduce attractiveness. Others have suggested that parrotfish can be attracted to the blocks and might bite off chunks of material. We have not had any problems with damage due to fish grazing or other animal activity in the areas that we have studied to date. As with any other technique, experience with the method will improve data quality.

The clod card measurement appears to integrate both turbulent agitation and unidirectional flow into a single number related to mass transfer. Water motion as measured with clod cards was shown to be a physical factor of primary importance controlling the distribution of reef corals at Johnston Atoll (Jokiel \& Tyler in press). Linear and oscillatory flow both appear to contribute to weight loss in the clods and their effects appear to be additive in a complex fashion. However, our laboratory and field investigations suggest that the 2 types of water motion may be 'biologically equivalent' per unit $D F$ for many biological processes that are limited by diffusion. More research is needed in this area. The method is not applicable to measurements of current direction and modulation. Certain types of data on current direction can be obtained with inexpensive techniques such as dye markers of drift cards. Measurement of fine-scale velocity changes (direction and modulation) must be carried out with much more expensive and sophisticated devices such as current meters and hot wire anemometers.

\section{LITERATURE CITED}

Agegian, C. R. (1985). The biogeochemical ecology of Porolithon gardineri (Foslie). Ph.D. dissertation, Univ. of Hawaii

Atkinson, M. J., Bilger, R. W. (1992). Effects of water velocity 
on phosphate uptake in coral reef communities. Limnol. Oceanogr. 37: 273-279

Doty, M. S. (1971). Measurement of water movement in reference to benthic algal growth. Bot. Mar. 14: 32-35

Gerard, V. A., Mann, K. H. (1979). Growth and production of Laminaria longicruris (Phaeophyta) populations exposed to different intensities of water movement. J Phycol. 15: $33-41$

Grovhoug, J. G. (1978). Piti power plant intake survey, November 1977. Naval Ocean Systems Center Tech. Rept 288. San Diego, CA

Jokiel, P. L. (1978). Effects of water motion of reef corals. J exp. mar. Biol. Ecol. 35: 87-97

Jokiel, P. L., Tyler III, W. A. (in press). Distribution of stony corals in Johnston Atoll lagoon. Proc. 7th int. Coral Reef Symp.

Kawai, H., Marui, M., Kurogi, M. (1982). Measurement of water movement with a hemispherical block of plaster. Jap. J. Phycol. 30: 161-162

This article was presented by C. Birkeland, Mangilao, Guam
McConnel, W. J., Siegler, W. F. (1959). Chlorophyll and productivity in a mountain river. Limnol. Oceanogr. 4: $335-351$

Morrissey, J. I. (1985). Carbon flow through fleshy macroalgae in coral reefs. Ph.D. dissertation, Univ. of Hawaij

Muus, B. J. (1968). A field method for measuring 'exposure' by means of plaster balls. A preliminary account. Sarsia $34: 61-68$

Patterson, M. R., Siebens, K. P., Olson, R. R. (1991). In situ measurements in reef corals. Limnol. Oceanogr. 36: $936-948$

Russo, A. R. (1977). Water flow and the distribution and abundance of echinoids (Genus Echinometra) on a Hawaiian reef. Aust. J. mar. Freshwat. Res. 28: 693-702

Santelices, B. (1977). Water movement and seasonal growth in Hawaii Mar. Biol. 43: 225-235

White, F. M. (1988). Heat and mass transfer. Addison-Wesley, New York

Manuscript first received: November 6, 1990

Revised version accepted: December 7, 1992 